Vol. LXVI 2015

\title{
TRANSMISSION TECHNIQUES FOR VAMOS GSM IN DOWNLINK
}

\author{
ENACHE Bianca \\ Faculty of Electronics and Telecommunications./Department Communications, "Politehnica" University, \\ Timisoara, Romania, enache.biancaemilia@gmail.com
}

\begin{abstract}
In this paper is presented a study of the transmission techniques for Vamos GSM. Are presented the advantages and disadvantages. The study was performed for the second generation:GSM(Global System for Mobile Communications). In order to observe the performance of the BTS equipment was performed a study of the DARP(Downlink Advanced Receiver Performance ) techniques and OSC(Orthogonal Sub Channel) influence.
\end{abstract}

Key words: Vamos, GSM, modulation, OSC, technique

\section{Introduction}

From mobile communications point of view there are 4 different generations: 2G,2.5G,3G and 4G. The 2G generation was the first one and it represents the most used mobile system communications. It is called GSM (Global System for Mobile Communications) and is based on circuit commutations. In figure 1 is represented the evolution of the GSM system in order to allow the Long Term Evolution (LTE)/4G development.

Figure 1: System evolution from GSM to LTE

\begin{tabular}{|c|c|c|c|c|c|c|}
\hline 2006 & 2007 & 2008 & 2009 & 2010 & 2011 & \\
\hline \multicolumn{7}{|c|}{ 3GPP GSM EDGE Radio Access Network Evolution } \\
\hline $\begin{array}{c}\text { EDGE } \\
\text { DL: } 474 \text { kbps } \\
\text { UL: } 474 \text { kpos }\end{array}$ & $\begin{array}{r}\text { Enhar } \\
E D G \\
D L 13 \\
U L .653 \\
\end{array}$ & & & & & EDGE \\
\hline \multicolumn{7}{|c|}{ 3GPP UMTS Radio Access Network Evolution } \\
\hline $\begin{array}{c}\text { HSDPA } \\
\text { OL } 144 \mathrm{Mbps} \\
\text { UL } 384 \mathrm{kpps} \\
\text { in } 5 \mathrm{MHz}\end{array}$ & $\begin{array}{c}\text { HSDPAHSSUPA } \\
\text { OL } 1444 \mathrm{Mbps} \\
\text { UL } 5.76 \mathrm{Mpps} \\
\text { in } 5 \mathrm{MHz}\end{array}$ & $\begin{array}{c}\text { HSPA Evolution } \\
\text { DL. 28 Mbops } \\
U .115 \mathrm{Mbps} \\
\text { in } 5 \mathrm{MHz}\end{array}$ & & & & HSPA \\
\hline \multicolumn{7}{|c|}{ 3GPP Long Term Evolution } \\
\hline & & & $\begin{array}{c}\text { LTE } \\
\text { DL. } 100 \mathrm{Mbps} \\
\text { U. } 50 \mathrm{Mbps} \\
\text { In } 20 \mathrm{MHz}\end{array}$ & & & LTE \\
\hline \multicolumn{7}{|c|}{ CDMA2000 Evolution } \\
\hline $\begin{array}{l}\text { EVDO Rev O } \\
\text { DL. 24 Mops } \\
\text { U. } 159 \mathrm{kpps} \\
\text { l. } 1.25 \mathrm{MHz}\end{array}$ & $\left(\begin{array}{l}\text { EVDO Rev A } \\
\text { DL . 3.1 Mops } \\
\text { UL } 1.8 \mathrm{Mbps} \\
\text { in } 1.25 \mathrm{MHz}\end{array}\right)$ & $\begin{array}{l}\text { EVDO Rev B } \\
\text { OL. } 14.7 \mathrm{Mbps} \\
\mathrm{U} .4 \mathrm{Mops} \\
\text { in } 5 \mathrm{MHz}\end{array}$ & $\begin{array}{l}\text { EVDO Rev C } \\
\text { DL. } 100 \mathrm{Mbps} \\
\text { UL } 50 \mathrm{Mbps} \\
\text { In } 20 \mathrm{MHz}\end{array}$ & $--\Rightarrow$ & UMB & UMB \\
\hline
\end{tabular}

Voice services over Adaptive Multi-user Channels on One Slot(VAMOS) is one of the most important features added in 3GPP standard Release 9 and doubles voice capacity for GSM. It comes with a new modulation scheme AQPSK(Adaptive QPSK) in downlink that enables allocation of different power levels in phase and quadrature. Using this modulation the GSM allows 4 users in the same timeslot. The Vamos impact can be illustrated in figure 2.

Figure 2: TDMA frames Half Rate(HR),Full Rate(FR) and VAMOS(HR+FR)

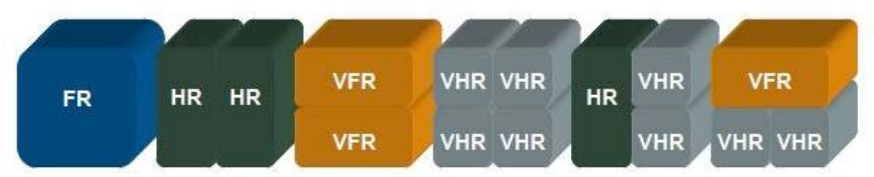

One of the keys in Vamos technology it's his compatibility with legacy terminals. This adapts the constellation of AQPSK modulation which distribute the power transmission between two subchannels of the AQPSK carrier. An extra power can be allocated to one of the channels. This mechanism is important because it allows mobiles legacy to operate using Vamos technique. 


\section{Downlink Transmission}

DARP(Downlink Advanced Receiver Performance) was developed for an improved reception of the mobile station when ACI(Adjacent Channel Interference) and CCI(Co-channel Interference) are present.

Even if it presents a good quality of the signal in downlink there are few advantages in DARP usage, but this concept is used to increase the vocal capacity. It works very well together with CCI with 0 $\mathrm{dB}$. It means that the network can have the same physical resource for two mobiles, but they will have different training sequences(Figure 3).

Figure 3: Channel quality for DARP co-TCH case

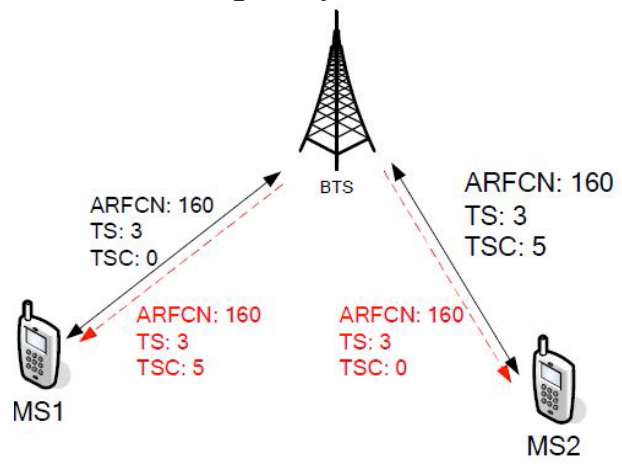

In downlink, each mobile station will consider the intended signal to be CCI but for the other one. The receiving mobile station will support only DARP improvements. For an optimal DARP performance, the two transmited signals for two different mobile stations should be out of phase with 90 degrees for the output of the channel pulse.

Figure 4: OSC with two simultaneous calls on the same radio channel

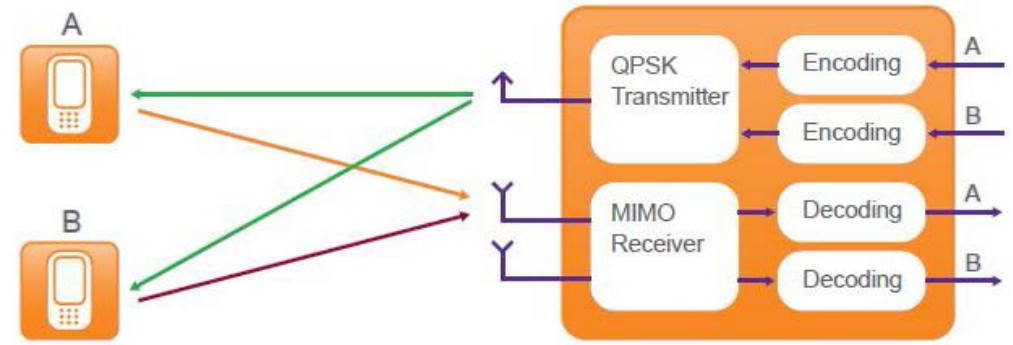

The advantages of OSC(Orthogonal Sub channel) usage:

-Improvement of the BTS equipment (Figure 5). This will increase the vocal capacity, more space for data traffic into the same TRX without affecting voice quality.

Figure 5: Channel capacity

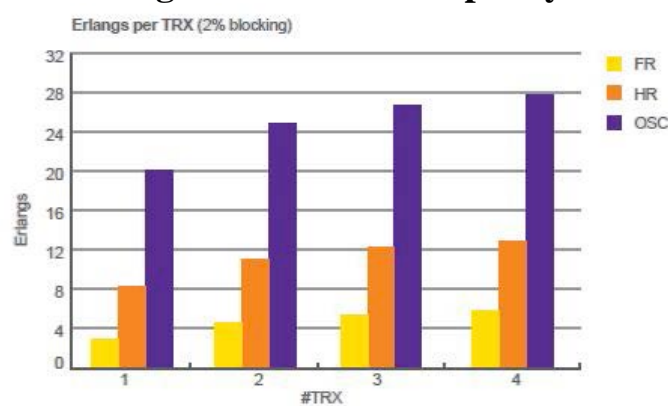

-spectral efficiency in Figure 6.

Figure 6: Spectral efficiency

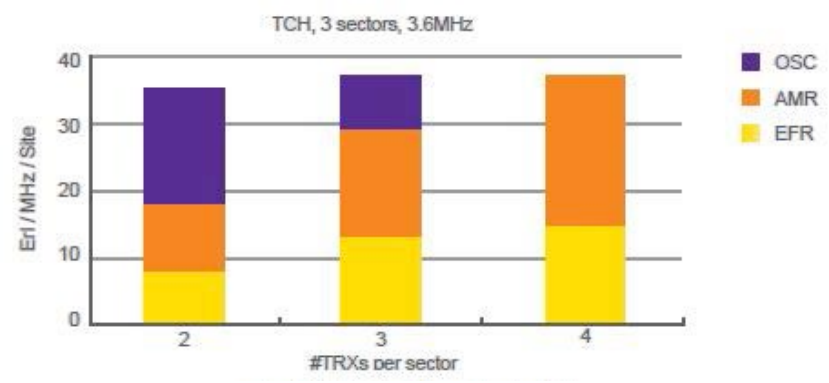


The VAMOS transmiter is presented in Figure 7. This method allows assign a channel communcations for simultaneous trasnmission for mobile terminals using TDM protocol(Time Division Multiplexing). After we established that the data must be transmited using our channel communication, to both mobiles. The data must be transmited only through the first mobile, it will be then directed to a second level of power which is defined for this case and with a lower value than the first one.

Figure 7: VAMOS Transmitter

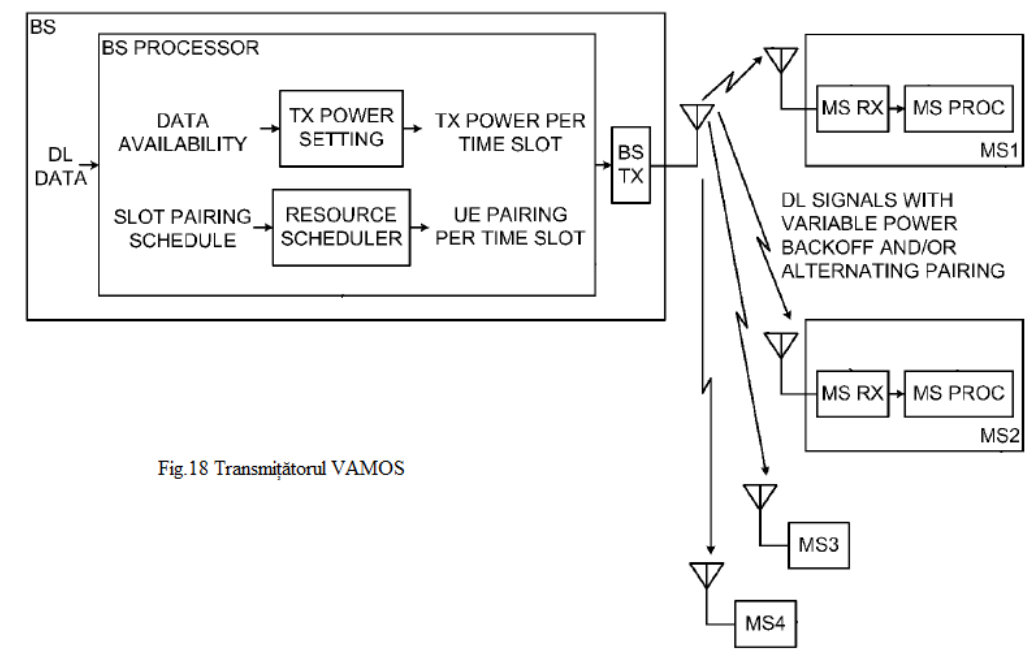

The algorithm scheme for implementing the transmission in downlink through a Vamos channel is presented in Figure 8.

Figure 8: Block diagram of transmitted da

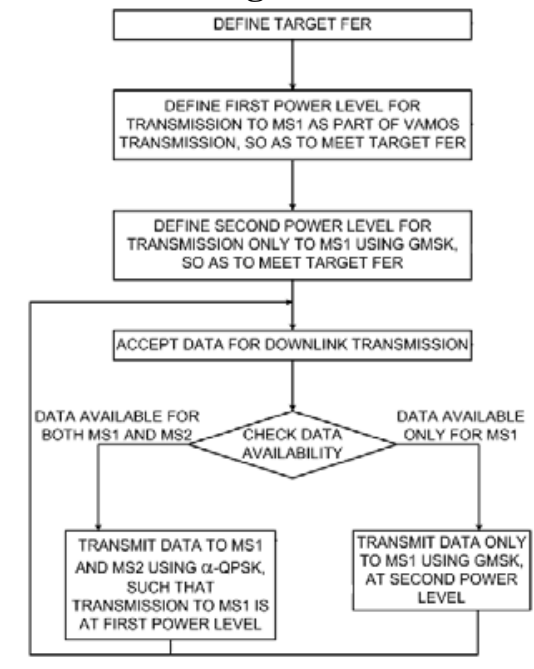

\section{Conclusions}

In GSM, the spectral efficiency of the voice is used for quantifying the number of vocal users that can be supported for a network/site/cell, for which is a given a certain frequency spectrum.

The GSM networks that are using AMR can work with reused frequencies. The AMR coding gives a better voice quality.

DARP represents an important step for the evolution of performance in downlink. With the DARP techniques, the mobiles can tolerate more interferences, which means that it works also in bad conditions. Together with AMR, DARP is able to present a good quality of the voice with very small values of Carrier Interference Ratio (Figure 9). 


\section{Figure 9: Spectral efficiency evolution in GSM}

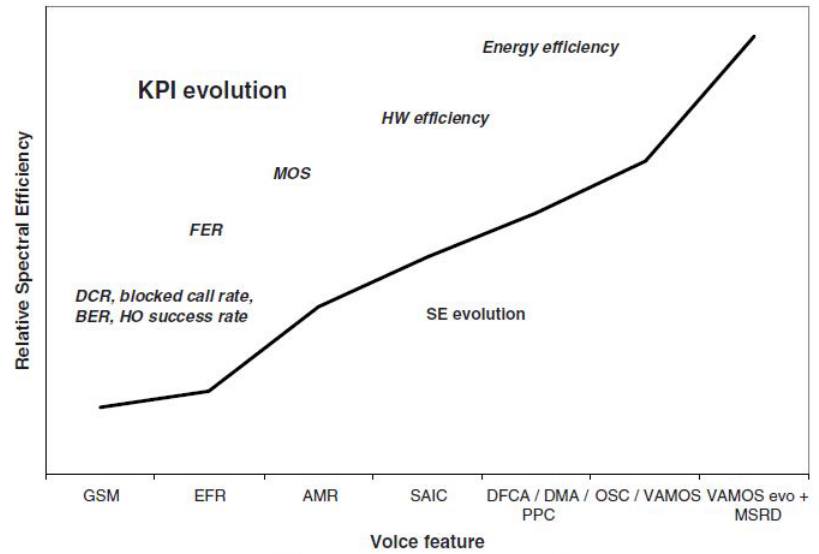

$\mathrm{DCR}=$ drop call rate

$\mathrm{BCR}=$ blocked call rate

$\mathrm{BER}=$ bit error rate

$\mathrm{FER}=$ frame erasure rate

MOS = mean opinion score

Also OSC and Vamos are doubling the number of voice channels for TRX which gives a huge improvement of the efficiency performance of the equipment. This two techniques reduce the interference.

\section{Acknowledgement}

This paper is supported by the Sectoral Operational Programme Human Resources Development POSDRU/159/1.5/S/137516 financed from the European Social Fund and by the Romanian Government.

\section{References}

- [1] Alcatel-Lucent trainings pentru Ericsson 3G RAN

- [2] Alcatel-Lucent trainings pentru WCDMA

- [3]http://www.rohde-schwarz.com/en/applications/vamos-technology-introductionapplication-

- note_56280-15776.html

- [4] http://www.telecomsemea.net/system/files/Ericsson_VAMOS_WP_0.pdf

- [5] GSM/EDGE evolution and performance, John Wiley\&Sons 2011, Mikko Saily,

- Guillaume Sebire, Dr. Eddie Riddington

- [6] GSM, GPRS and EDGE Performance 2nd Ed, John Wiley\&Sons 2003, Edited by T.

- Halonen, J. Romero and J. Melero

- [7] 3GPP standard Release 8 (2009-09)

- [8] GSM/EDGE: A mobile communications system determined to stay, Wolfgang

- Gerstacker, Robert Schober, Raimund Meyer, Frank Obernosterer, Michael Ruder, Hans

- Kalveram

- [9] US Patent: VAMOS transmission schemes - US2011/0044299

- [10] US Patent: Receiver for MUROS - US2011/0255641

- [11]http://www.nokiasiemensnetworks.com/NR/rdonlyres/FFB751DF-E839-41C7-A7F4-

- D3B9B9490266/0/OSC_TechnologyBrief_v10.pdf 